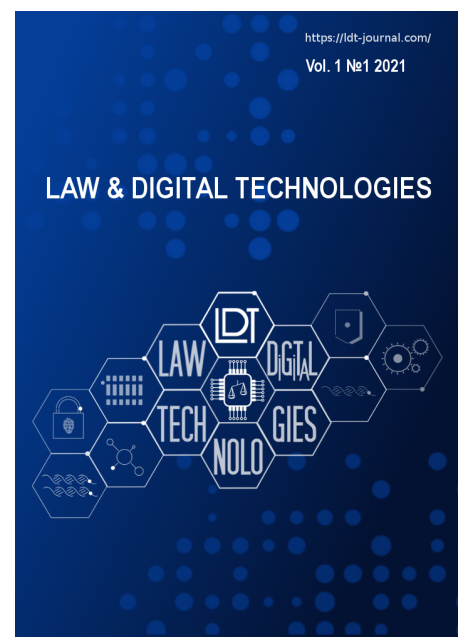

Law \& Digital Technologies. 2013-2023

ISSN 2782--2907

URL - $\underline{\text { http://1dt-journal.com }}$

All right reserved

№ 1 Volume 1. 2021

\title{
Digital Assets and Digital Inheritance
}

\section{Julia S. Kharitonova}

Lomonosov Moscow state University

Moscow, Russia

\section{Abstract}

The paper reveals the concept of "digital inheritance" - a new term in law, which has become widespread in many legal systems and refers to the transfer of rights to digital assets in a broad sense. It is established that only turnable digital assets are subject to transfer by way of universal succession. It is shown that the possibility of digital inheritance by law and by will is limited depending on the object by the terms of the contract (a license, services, confidentiality) and/or the human constitutional right to privacy.

Keywords list (en): digital assets, digital inheritance, social network account, digital content, privacy

Date of publication: 02.07.2021

\section{Acknowledgment:}

Статья подготовлена по гранту РФФИ № 18-29-16145 мк. Тема: «Механизм правового регулирования отношений с использованием технологии распределенных реестров».

\section{Citation link:}

Kharitonova J. Digital Assets and Digital Inheritance // Law \& Digital Technologies. 2021. - V. 1. - № 1 C. 19-26 . URL: https://ldt-journal.com/s123456780015732-6-1/. DOI: $10.18254 / \mathrm{S} 123456780015732-6$ 
Digital assets are becoming more and more valuable to the modern society. And while in Russia this topic has only recently become popular among lawyers, outside the country this trend has been developing for several decades. In 2011, the Center for Creative and Social Technologies (CAST) in the UK (Goldsmiths, University of London) published a study on the Internet use in the UK called "Generation Cloud". The study found that Brits have at least $£ 2.3$ billion worth of digital possessions stored in the cloud. Meanwhile, 24\% of UK adults believed they had a digital asset worth more than $£ 200$ per person (Rackpace Hosting 2011). PricewaterhouseCoopers (PwC) conducted a similar survey in 2013 and found that people value their digital assets at £25 (PWC 2013). We see a similar situation in other European countries (Nemeth et al. 2017) and in the USA. Moreover, suggestions concerning the current situation of digital inheritance are put forward in views of Internet companies, users, and the government in China (Zhao and Yang 2012; Wei-jie 2012). Considering the size of this market segment, owners are concerned about what happens to our Facebook, Twitter, LinkedIn and other social media accounts after death, to whom and how digital assets, including tokens and cryptocurrency, can be transferred. The problem is all the more urgent because losing passwords for the access to asset depositories, digital platforms, etc. can be fatal (Sarnek 2016). In Russian literature, the problem of inheritance of digital assets is considered through the prism of Articles 128 and 141.1 of the Civil Code of the Russian Federation. In particular, Yatsenko (2019) concludes that since the Russian legislation defines a digital right as a token, it is the only one of all digital assets in our legal order "capable of being an autonomous object of inheritance. At the same time, the heirs may realize the possibilities inherent in it concerning another object associated with it, for example, by exercising the right of ownership to a car certified by a token". This approach seems very narrow. By today, practicing lawyers, notaries, and citizens are faced with questions of the possibility of succession in respect of such specific digital assets as cryptocurrencies, tokens, social media accounts, and virtual gaming assets. In recent years, many countries have discussed in some detail the possibility of universal succession of social media assets and other digital assets. The term "digital inheritance" has been developed in foreign legal literature to denote the relevant direction.

\section{The concept of digital assets in a broad and narrow sense}

4 The process of digitalization of the economy has led to the creation of new objects of wealth circulation, which have received the common name - digital assets. At the same time, there is no unified approach to the understanding of digital assets in the current literature. As the most important features of digital assets a "binary" form of their existence and the presence of real or potential value are rightly pointed out. It is these features that are reflected in the very name of the new property objects. However, these features are not enough to unambiguously qualify objects existing in the binary form as digital assets. According to the literature, digital assets include not only tokens and cryptocurrencies, Big Data, domain names and social media accounts, virtual gaming property, but also, a digital content, i.e. information stored on Web resources (texts, video and audio files, graphic images, animations, and so on). But this, in our opinion, is not always reasonable. The designation of any digital object as a digital asset is largely driven by the legal definition of digital assets contained in the Revised Uniform Fiduciary Access to Digital Assets Act (RUFADAA 2014). According to (h) Section 870 of the Act, "Digital asset" means an electronic record in which an individual 
has a right or interest. The term "digital asset" does not include an underlying asset or liability unless the asset or liability is itself an electronic record. A "record," however, means information that is recorded on a tangible storage device or stored on an electronic or other medium and is removable in a perceptible form (r) Section 870. Consequently, «a digital asset is anything that can be stored and transmitted electronically (using a computer) that can be owned and thus, can have ownership and usage rights associated with it» (Ibáñez et al. 2018). A broad approach to the concept of digital assets is also demonstrated by Russian legal scholars. So, Laptev (2018) distinguishes: "cryptocurrencies (bitcoin, ethereum, and so on); shares, bonds, shares in the authorized capital of corporations; tokens (financial assets issued by a legal entity or individual entrepreneur to attract investment); intellectual property (for example, musical works, works of art, books); photos; electronic insurance policies; smartcontract (here smart contract is considered not as a transaction, but as an independent object of law that has value); personal data; loyalty points, etc." It seems that the range of phenomena related to digital assets depends mostly on the purpose of classification. For the protection of the right to digital assets by restricting access to them, it is reasonable to define this concept as widely as possible, thereby ensuring higher security. However, legal regulation of such digital assets as tokens and cryptocurrencies requires special provisions that consider the specifics of financial relations. For other purposes, researchers can identify different types of digital assets. So, Ruan (2019) outlines the following as the types of digital assets: networked system assets, software assets; hardware assets; service assets; robotic assets; data assets, metadata assets, digitallyenabled devices. It should be noted that when ordinary objects of civil rights get a new form such as digital (electronic), there are specific problems associated with their legal regulation. From this point of view, their recognition as digital assets can be entirely substantiated. But then the concept of digital assets in a broad and restricted sense shall be distinguished. In a broad sense, any objects of property turnover that exist in the digital (electronic) form can be referred to as digital assets. In a restricted sense, digital assets should be understood as new economic objects established using digital technologies. Outlining of digital assets category in a restricted sense is necessary, first of all, to distinguish new objects of property circulation that require the establishment of an appropriate legal regime from those objects of civil rights, which do not require a new legal regime despite undergone modification as a result of digitalization. These may include tokens, cryptocurrency, Big Data, domain names and social media accounts, virtual gaming property, etc. For the purpose of ensuring the stability of their property turnover, it is required to create a special legal regime either by adapting the existing norms of civil legislation or by creating new rules. First of all, to solve this problem it is necessary to identify their legal nature, distinguishing them from the already known legal phenomena in a digital form, which have received a proper legal regulation. That will allow us to form both conceptual approaches to regulating relations, the object of which are digital assets, and proposals for the creation of special legal regimes for certain types of digital assets. The Russian legislator is on the way to solve this problem. In particular, Article 6 of the Digital Financial Assets Act states that it is allowed to issue a certificate of succession, providing for the transfer of digital financial assets of a specific type in the order of universal succession (Federal Law of the Russian Federation of 31.07.2020 No 259-FZ "On Digital Financial Assets, Digital Currency and on Amendments to Certain Legislative Acts of the Russian Federation»). 


\section{Digital Assets vs Intellectual Property}

6 As a feature of digital assets, the legal literature often points out that they have such a close relationship to software that they are themselves objects of intellectual property (Saveliev 2017). Looking at digital assets as at intellectual property allows us to see some patterns and clarify our position on the nature of the relevant types of assets. For example, cryptocurrency is often presented as the result of a computer program work, i.e., the result of applying an intellectual property object. Indeed, without using a computer program designed to produce coins (virtual money units) of a cryptocurrency, it is simply unthinkable to achieve a result. Simultaneously, the peculiarity of cryptocurrency as a digital asset is that it is created for the widest distribution based on the so-called open-source code. Software that allows creating a cryptocurrency is distributed widely, which, in turn, usually does not generate a monopoly of the creator on the result of the application of the corresponding program - a tool in the form of coin records. Cryptocurrency and tokens were also considered in the context of the legal regime of the database. Can bitcoins be considered to be subject to the IP right of the database holder? The application of distributed ledger technology in practice means that the computer disk of each member of the system stores its own copy of a common database of transactions, which are synchronized with each other when the next block is formed. The chain of transaction blocks constitutes a database that is stored not on one server but is distributed across all devices (computers) on the network. From a practical point of view, cryptocurrency can be defined as bounded records in a database, carried out uniquely in a virtual payment system. It seems that establishing a legal regime of intellectual property concerning crypto-assets is not reasonable and contrary to their nature. In this case, the monopolist's right for the computer program should be recognized as exhausted to not complicate the circulation of crypto-assets as some universal nominal units. And in all cases, when dealing with cryptoassets, we are talking about an open source software that helps create cryptocurrency and tokens. Similar problems arise with regard to the definition of Big Data as a substratum of databases and objects of the monopoly of their compilers. Persons who aggregate open data on the Internet often insist on the existence of their exclusive IP right to such datasets, which is highly controversial. Having considered the relationship between the concepts of "digital assets" and "intellectual property," we come to the following conclusions. All objects existing as the results of intellectual activity in a digital form, as part of the software code, circulate in the market within specific platforms and can be classified depending on their economic function and the need to establish a legal monopoly of the author-developer of the software into the following groups: 1) Protected results from creations of the human mind, which are not digital assets (the legal regime of IP is established by the Civil Code of the Russian Federation, the rights protected by copyright are the object of turnover, and do not have an independent value compared to other exclusive IP rights, which exist in a non-digital form); 2) virtual game property as a type of digital asset, limited to the framework of the virtual world (has the features as property in the virtual space, sometimes is the result of a creative activity of the player, its circulation is subject to the terms of the license agreement of the player and the publisher of the game, the purpose of its creation is limited to the virtual world, not the establishment of the monopoly of the author, as it is inextricably linked to the monopoly of the publisher and the framework of the license agreement, but protected as a personal right of a person to property with a value); 3) digital assets in the form of cryptocurrency 
and tokens (created as part of computer programs, intended for a wide circulation in the market, have no characteristics as objects of intellectual property rights, and created based on an open-source software license). Thus, depending on the purposes of determining the legal regime of the asset, we are either dealing with a digital asset, as it is defined in this paper, or only with the result from creations of the human mind, to which the IP right of the creator, participating in the circulation in this capacity, is established. In this case, the IP right is not a digital asset but an intangible asset regime for other purposes. Therefore, 3D models can be defined as objects of exclusive rights for the purposes of reproduction and use by other persons than the right holder, and as objects of circulation in the virtual world within the rules of the game, being digital assets in themselves, as players do not need the right to replicate or reproduce works, but the ability to transfer to the functionality in the game. And the more potent the influence of the legal regime of intellectual property on the object of the relationship, the less negotiable the digital asset is.

\section{$7 \quad$ What does "digital inheritance" mean?}

8 Conceptually, the concept of digital assets is a relatively new phenomenon in Russia and worldwide. Scientists and law enforcers recognize that the law lacks a proper legal definition of the criteria for referring digital objects to the objects of legal relations. In foreign literature, "digital inheritance" refers to universal succession both concerning tokens and cryptocurrencies and concerning "emails and messages in messengers, emails in email services, electronic bank cards; photo albums posted on Instagram and cloud services; music selections on services and in applications" (Berlee 2017) and others. One may even get the feeling that any object (a social media account, a file, a document, a digital footprint on social networks) that exists in the heir's possession is inherited (Santos Moron, 2018). But this is only partially true. That is, not any object that exists in the digital form can be included in the inheritance estate as having value of a "personal, economic, or social connection with a person" (Harbinja 2017). The term "digital inheritance" is not used in the legislation of Russia and foreign countries. Preferably, this term is used as a collective term to address in practice legal issues related to succession to digital assets. That suggests that the legal regime of "digital inheritance" would have to include provisions that apply to the inheritance relationships in an ordinary way. However, when it comes to digital assets, intellectual property law, personal data protection, and privacy regulations must also be taken into consideration. The most important aspect of the issue is that digital assets as objects of subjective rights for different purposes are defined differently. We can distinguish between a narrow and a broad concept of digital assets. In the current literature, the "binary" form of their existence and the presence of a real or potential value are pointed out as essential features of digital assets. That is the broadest view of the turnover of digital assets. This approach defines the objects in question very broadly but has been adopted by many legislative analysts. For example, English literature draws attention to the fact that several attempts have been made to define and classify digital assets so far. But due to the fact that most of the definitions have been inductive in nature, whose authors have started from existing assets on the Internet, trying to make appropriate generalizations, the Law Commission of the British Parliament has taken the position that a comprehensive formal definition of this kind of object is unnecessary. At the same time, the broad approach to the definition of digital objects does not allow us to distinguish 
new objects that require the creation of a legal regime from those objects of civil rights, which, although they have undergone modification as a result of digitalization, but do not need to create new legal norms (for example, the results of intellectual activity). In this regard, digital assets' legal essence, in the narrow sense as objects of civil rights, is the presence of their specific features: the economic value, the ability to turnover, the exclusively digital nature, extraterritoriality (Sannikova and Kharitonova 2018a; Sannikova and Kharitonova 2018b). These attributes allowed us to determine the range of digital assets that need the creation of special civil legal regimes: crypto-assets (tokens and cryptocurrencies); big data; domain names and social media accounts; and virtual game property. In view of the above, we can say that digital inheritance is a generalized mechanism of transfer in the order of universal succession of digital assets in the broadest sense, but when it comes to digital inheritance, it is necessary to distinguish the features of the legal regime of specific objects that are part of the inheritance.

\section{$9 \quad$ Types of inherited digital assets}

10 Modern man possesses a vast arsenal of means and platforms allowing the creation, acquisition, and transfer of information objects existing in electronic or binary form. From the law point of view, these objects can be divided into several subgroups to determine the possibilities of succession concerning them: 1) personal accounts on social networks and digital media sites (Spotify, Netflix), multiplayer virtual games, domain names; 2) content on social media pages (diaries and fact posts), a cloud storage (music, videos, photos, and so on, created by the testator her/himself or obtained under a license agreement), a software; 3) other digital objects that are in circulation within digital platforms and access to which is associated with the need to obtain a login and password (cryptocurrency wallets, tokens, and so on - digital assets in the narrow sense). In the literature, all cases of access to these assets are considered as access to the testator's property (Marchisotti 2016), not as property in itself. In this, foreign researchers radically differ in their understanding of digital assets from Russian scientists. After all, when analyzing this phenomenon in Russia, it is generally accepted to talk about the tokenization of things, involving creating a new digital "form of expression" for the classical objects of civil rights. In our opinion, this identification of digital assets with things attempts to equate the legal regime of a digital asset with property leads to false assertions that "the digital sign or token (not paired with another object of law) itself does not have any own significance or utility, it lacks independence" (Novoselova and Polezhaev 2019) and can be regarded as an act of the state registration. On the contrary, in Europe and the United States, it is generally accepted to consider digital assets as having an independent value and with different legal regimes objects of legal relations (Sannikova and Kharitonova 2018a). When addressing the issue of social media account inheritance possibilities, the critical question was actively debated: whether or not the content and/or user account can be treated as property. By now, it has been recognized that user accounts are created based on contracts between service providers and legacy users. The account itself and the underlying software is the intellectual property of the service provider (Navas 2019). Rights from agreements defining the right of access to certain resources and platforms of media services, streaming, etc., are included in the inheritance estate. Here the rules of inheritance of property rights of claim from contracts linking the user - the heir with a provider or a 
social network are possible to apply (Patti and Bartolini 2019). Digital content is generally defined as the result from creations of the human mind. Obviously, some of the designated objects are the results from creations of the human mind protected as objects of exclusive IP rights (photos, videos, texts, and so on). That means that exclusive rights to the relevant objects may be inherited to the extent existing from the moment of the inheritance opening. In this regard, it should be noted that there are often difficulties in answering the question about the right holder concerning a digital content. After all, if the content includes objects created not by the heir, but by other persons, or the heir's rights to which are temporary in connection with the license agreement, such exclusive rights may pass to the new right holder in the volume and order established by law. It is also possible to transfer cryptocurrency or tokens by gaining access to digital platforms, cryptocurrency wallets, applications, and so on.

\section{$11 \quad$ Succession of digital inheritance}

12 As a general rule, in most states, heirs receive by succession all transferable rights, all property possessed by the deceased. That means that heirs do not need to transfer individual assets or property as a whole, nor do they need to transfer copyrights or obligations. With succession, the heirs simply step into the testator's shoes. Under Article 1112 of the Civil Code of the Russian Federation, the inheritance includes things that belonged to the testator on the day of opening the inheritance, other property, including property rights and obligations. Similar rules are contained in other legal orders (for example, see $\S 1922$ of the German Civil Code). Consequently, in the absence of the special regulation, digital assets that have the property of turnover (not inextricably linked with the testator's personality) can be inherited. Features of the transfer of rights to some of the digital assets associated with the transfer of personal or other information, as constituting the assets themselves' content, and accompanying access to these assets (login, password). Also, a lot of content is just personal data and information. Heirs may not have access to this content at all or even be unaware of the content included in the deceased's account. As established in legal doctrine and theory, this type of content cannot be considered an object of civil rights, and therefore cannot be transferable through the usual mechanism of legal and testamentary inheritance (Harbinja 2017). The mentioned objects may contain information constituting both personal data and information about the private life of third parties who are not part of the circle of heirs (for example, communication partners). At the same time, it should be taken into account that the information both posted on social networking pages and reported by the user during registration may contain personal or private data, the dissemination of which, including among the heirs, may be undesirable for the deceased. These relations will not be subject to the rules on the inheritance of property, but the issue of the admissibility of disclosure of information to heirs by the holders of this information will need to be resolved. In foreign law, this problem is currently being debated. The Italian inheritance law contains rules on the transfer of the personal data of the deceased. The rights relating to the deceased's personal data may be exercised by persons who act in their own interest or to protect the deceased's interests or for other reasons worthy of protection. However, the general GDPR does not establish specific rules on the transfer of the deceased's data. As is well known, the General Data Protection Regulation of 2016 (GDPR) does not apply to the personal data of deceased persons. It is therefore left to the Member States to provide for rules regarding the 
processing of the personal data of the deceased. Notwithstanding the absence of European indications on the specific issue, the GDPR has encouraged national legislatures to adopt specific measures regarding data protection for deceased persons. For example, in this framework, the Italian legislature recently enacted an interesting set of rules through Legislative Decree No 101 of 2018 on the adaptation of national laws to the GDPR: 'Disposizioni per l'adeguamento della normativa nazionale alle disposizioni del regolamento (UE) 2016/679 del Parlamento europeo e del Consiglio, del 27 aprile 2016, relativo alla protezione delle persone fisiche con riguardo al trattamento dei dati personali, nonché alla libera circolazione di tali dati e che abroga la direttiva 95/46/CE' (regolamento generale sulla protezione dei dati) (GU (Gazzetta ufficiale) Serie Generale n. 205 del 4.9.2018) (Decreto legislativo 10 agosto 2018, n. 101). Under the principle of universal succession, everything that belonged to decedent can belong to his or her heirs unless it is explicitly regulated otherwise or rights are strictly personal. Despite this principle, there are some rights in the digital world that cannot belong to the heirs (Vučković and Kanceljak 2019). Thus, the inheritance of digital assets is limited by the possibilities of their negotiability. Often the informational nature of a digital asset prevents its transfer to third parties beyond the owner's will. Therefore, it is possible to divide digital assets into those that are freely circulated on the market (for example, cryptocurrency) and those restricted in circulation due to their close connection with the person of the testator (for example, social network accounts).

\section{$13 \quad$ Inheritance by law and by will}

14 In the case of digital inheritance by will, the testator determines the methods and objects subject to specific persons in advance. At the same time, s/he can specify logins and passwords for access to the account or cryptocurrency. The lack of a password recovery mechanism could be a severe problem for the heirs and creditors of the deceased. For example, according to media reports, QuadrigaCX customers could lose $\$ 190$ million invested in the cryptocurrency following CEO Gerald Cotten's death. According to the testimony of a surviving spouse, G. Cotten was the only key to getting the money. You have to admit that Cotten took a thorough approach to protect the information. The cold storage, versus its hot wallet, where the digital assets are stored, was not hacked during his lifetime and cannot be accessed now. In order to avoid such problems, if the holder of a digital asset abroad has the will, it is allowed to reflect a unique access code to the registry in his or her will. For example, under the Uniform Fiduciary Access to Digital Assets Act (FADA) in the US, there is a right for holders of digital assets to provide information to their custodians about the persons who are entitled to access these assets (social network accounts, payment systems, and email services) (Pike 2014). Russian law does not prohibit the listing in the will of data related to the provision of access to resources on the Internet to obtain digital assets. However, according to the Dutch notary community, the inclusion of digital assets in a will is an obvious choice for clients. But when planning a digital inheritance, there are some peculiarities to consider. For example, a will is pronounced publicly after a person's death, so many people may be aware of confidential and private information regarding the deceased person's digital assets. Also, when it comes to digital assets stored in Internet service provider accounts, making death plans won't matter much because the Internet service provider has rules that prohibit access to those accounts by anyone other than the original user as part of the agreements (Klasicek 2018). Therefore, in the 
Netherlands, the Association of Notaries has supported the development of a "digital repository" in which clients can store their digital data, including access codes, without being subject to direct probate rules. This service allows you not to set up a digital inheritance strategy for each of your online personal accounts, but rather collect all of your key logins (Berlee 2017), passwords and files in one highly secure location and then set up an inheritance function, identify beneficiaries, such as relatives or business partners, and transfer important files or passwords to them upon your death. The data transfer is automatic and secured with an activation code that the heir has provided to a trusted person, close relative or others (DSwiss 2018). According to Italian law, access to the account can be considered as a part of the estate (Camardi 2018). In principle, after the reform Italian law does not solve the problems of access to personal data through the general inheritance law of the Civil Code 14. A particular provision on data protection must be taken into consideration in the first place. As mentioned above, according to Legislative Decree No 101 of 2018, the rights encompassed within Articles 15-22 GDPR that are related to deceased persons could be exercised by persons who act in their own interest or act to protect the interests of the deceased (Patti and Bartolini 2019). Due to the wording used by the Italian legislature to describe the requirements of consent to exclude the application of the special provisions on post mortem data protection, it seems that the existence of an effective willingness to derogate from the general rule will be strictly controlled. Russian law does not specify if digital rights or other property cannot be inherited. The exceptions established in the law do not apply to digital assets. The question often arises as to whether cryptocurrency and tokens can be mentioned in a will and whether corresponding rights to digital assets can be reflected in the certificate of inheritance. Singular succession under a will is also permissible, which with respect to digital assets can be considered from a legatee perspective - when a certain person is authorized by the testator. Notaries recommend disclosing what should happen to the digital asset after death (delete or create a memory page) and who will be the "executor of the social media will": one of your relatives or the notary. In our opinion, guided by the Principles of Legislation of the Russian Federation on Notaries and the provisions of the Methodological Recommendations on registration of inheritance rights, we can conclude that at present, the indication in the certificate for the right to inherit digital assets is not necessary. Digital assets, according to Article 128 of the Civil Code of the Russian Federation, are included in the concept of property, which will positively affect the formation of the practice of transfer of these objects in the order of inheritance succession. Under Clause 13.2 of the Methodological Recommendations, certificate of right to inheritance is issued to heirs who have accepted the inheritance following the rules of civil legislation of the Russian Federation, and is a document confirming the right to the specified inheritance, which includes the following belonging to the testator on the day of opening the inheritance: things, including cash and certificated securities; other property, including non-cash funds; uncertificated securities (Art. 128 Civil Code of the Russian Federation); property rights (including rights arising from contracts concluded by the testator, unless otherwise stipulated by law or contract; exclusive rights to the results of intellectual activity or means of individualization; rights to receive money awarded to the testator, but not received by him) and obligations; other property, inheritance of which is allowed by law. The certificate may not specify the specific inherited property (the heir may not be aware of specific components of the inherited estate). A certificate for individual objects 
is necessary when particular objects from the inherited estate go to an individual heir under the will or when the heirs have divided the inherited property. The forms of certificate of right to inheritance are approved by Order of the Ministry of Justice of RF as of 10.04.2002 No 99 and allow the description of inherited property to be given as "... whatever it consists of and wherever it is located", which also testifies in favor of inheriting digital assets in Russia. However, the problem may be a disclaimer that forms with a free definition of the inherited property. Without listing specific objects of rights, they are not suitable for confirming the right to inherit those opened abroad. In all other cases, the certificate must indicate for which objects it is issued.

\section{Conclusion}

16 Despite the growing value and importance of digital assets in circulation, from a legal point of view the situation has remained very vague until recently. The reason seems to lie in the peculiarities of the emerging legal relations, the heterogeneity of digital assets and the conflict arising from the law between the rules of succession, contract law, intellectual property and personal data protection rules. The possibilities of digital inheritance by law and by will are limited depending on the object by the terms of the contract (a license, services, privacy) and/or the constitutional right of individuals to privacy.

\section{$17 \quad$ Acknowledgements}

18 This research was supported by the Russian Foundation for Basic Research via grant No 18-29-16145 MK «The Mechanism of legal regulation of relations using the Distributed Ledger Technology».

19

\section{References}

20 Berlee, Anna. 2017. Digital Inheritance in the Netherlands. Journal of European Consumer and Market Law 6: 256-260. $\gg \gg>$ Camardi, Carmelita C. 2018. L'eredità digitale. Tra reale e virtuale. Il diritto dell'informazione e dell'informatica 1: 65-93. Resta, Giorgio. 2019. La successione nei rapporti digitali e la tutela post-mortale dei dati personali. Contratto e impresa 35 (1): 85-105.

\section{Digitale nalatenschap. $\gg \gg>$}

DSwiss. 2018. Data inheritance on different online platforms. $\gg \gg>$ Harbinja, Edina. 2017. Post-mortem social media: law and Facebook after death. In The Legal Challenges of Social Media, edited by David Mangan, Lorna Gillies. Cheltenham: Edward Elgar. Harbinja, Edina. 2017. "Legal aspects of transmission of digital assets on death." Doctoral diss., University of Strathclyde. $\gg \gg>$ Ibáñez, Luis-Daniel Ibáñez, Michał R. Hoffman and Taufiq Choudhr. 2018. Blockchains and Digital Assets. $\gg>>$ Klasicek, Dubravka. 2018. "Digital inheritance." In Proceedings of the Interdisciplinary Management Research XIV (IMR, 2018), Opatija, Croatia, November, 2018, 1050-1068. Laptev, Vasily. 2018. Digital assets as objects of the civil rights. Legal science and practice: Journal of Nizhny Novgorod academy of the Ministry of internal affairs of Russia 42(2): 199-204. Marchisotti, Chiara. 2016. Digital identity and posthumous protection. In Identità ed eredità digitali: Stato dell'arte e possibili soluzioni al servizio del Cittadino, edited by Oreste Pollicino, Valerio Lubello, Marco Bassini Canterano. 
$\gg \gg$ Navas, Susana. 2019. Digital Content of the Inheritance: Remarks on the Judgment of the German Federal Court of Justice (BGH) of 12 July 2018 from the Standpoint of Spanish Law. European Review of Private Law 27(5): 1159 - 1168. Nemeth, Kristin and Jorge Morais Carvalho. 2017. Digital inheritance in the European Union. Journal of European Consumer and Market Law 6(6): 253-260. Novoselova, Ludmila and Oleg Polezhaev. 2019. Digital signs as objects of civil rights. Entrepreneurial Law 4: 3-12. Patti, Francesco Paolo and Francesca Bartolini. 2019. Digital Inheritance and Post Mortem Data Protection: The Italian Reform. European Review of Private Law (ERPL), Forthcoming. https://papers.ssrn.com/sol3/papers.cfm? abstract_id=3397974 Pike, George. 2014. Legal Issues: What to Do with Your Digital Life. $\gg \gg \gg$ PWC. 2013. "Digital lives: we value our assets at $£ 25$ billion." Accessed May 12, 2021. $\gg \gg>$ Rackpace Hosting. 2011. "Generation Cloud: A social study into the impact of cloud-based services on everyday UK life." Accessed April 15, 2021. https://slidex.tips/download/generation-cloud-a-social-study-into-the-impact-of-cloudbased-services-on-every Revised Uniform Fiduciary Access to Digital Assets Act (RUFADAA, 2014) Accessed April 2021. https://leginfo.legislature.ca.gov/faces/billTextClient.xhtml Ruan, Keyun. 2019. Digital Asset Valuation and Cyber Risk Measurement: Principles of Cybernomics. Academic Press. Sannikova, Larisa and Julia Kharitonova. 2018a. The legal entity of new digital assets. Law 9: 86-95. Sannikova, Larisa and Julia Kharitonova. 2018b. Protection of digital assets as property value. Economy and law 5: 26-35. Santos Moron, María. 2018. The So-Called Digital Inheritance: Need of Regulation: Study of Spanish and Comparative Law. Cuadernos Derecho Transnacional 10(1): 413-438. Sarnek, Marcin. 2016. When You Are Not What You Do Not Have: Some Remarks on Digital Inheritance. In Materiality and Popular Culture: The Popular Life of Things, edited by Anna Malinowska, Karolina Lebek. New York: Routledge. Saveliev Alexander. 2017. Cryptocurrencies in the system of civil rights objects. Law 8: 136-153. Vučković, Romana and Ivana Kanceljak. 2019. Does the right to use digital content affect our digital inheritance? EU and comparative law issues and challenges series (ECLIC) 3: 724-746. https://doi.org/10.25234/eclic/9029 Wei-jie, Wang. 2012. Research on the Present Situation of Chinese Digital Inheritance. http://en.cnki.com.cn/Article_en/CJFDTOTAL-QBKX201201009.htm Yatsenko, Tatyana. 2019. Inheritance of digital rights. Inheritance Law 2: 11-14. Zhao, Li, Xi-ye Li and Shu-hui Yang. 2012. Succession of Digital Inheritance Involving Accounts. Journal of Beijing University of Posts and Telecommunications (Social Sciences Edition) 14 (3): 33-39. $\gg \gg>$

\section{References:}

1. Berlee, Anna. 2017. Digital Inheritance in the Netherlands. Journal of European Consumer and Market Law 6: 256-260. https://ssrn.com/abstract=3082802

2. Camardi, Carmelita C. 2018. LTeredit? digitale. Tra reale e virtuale. Il diritto dell'informazione e dell'informatica 1: 65-93.

3. Resta, Giorgio. 2019. La successione nei rapporti digitali e la tutela post-mortale dei dati personali. Contratto e impresa 35 (1): 85-105. 
4. Digitale nalatenschap. https://www.notaris.nl/testament/digitale-nalatenschap

5. DSwiss. 2018. Data inheritance on different online platforms. https://www.securesafe.com/en/news/digital-inheritance-policies/

6. Harbinja, Edina. 2017. Post-mortem social media: law and Facebook after death. InaThe Legal Challenges of Social Media, edited by David Mangan, Lorna Gillies. Cheltenham: Edward Elgar.

7. Harbinja, Edina. 2017.aULegal aspects of transmission of digital assets on death.FaDoctoral diss., University of Strathclyde. http://digitool.lib.strath.ac.uk/R/? $\underline{\text { func }=\text { dbin-jump-full\&object id }=28644}$

8. Ib??ez, Luis-Daniel Ib??ez, Micha? R. Hoffman and Taufiq Choudhr. 2018. Blockchains and Digital Assets.

https://www.eublockchainforum.eu/sites/default/files/researchpaper/blockchains and digital assets_june version.pdf

9. Klasicek, Dubravka. 2018. UDigital inheritance.F In Proceedings of the Interdisciplinary Management Research XIV (IMR, 2018), Opatija, Croatia, November, 2018, 1050-1068.

10. Laptev, Vasily. 2018. Digital assets as objects of the civil rights. Legal science and practice: Journal of Nizhny Novgorod academy of the Ministry of internal affairs of Russia 42(2): 199-204.

11. Marchisotti, Chiara. 2016. Digital identity and posthumous protection.a In Identit? ed eredit? digitali: Stato dellTarte e possibili soluzioni al servizio del Cittadino, edited by Oreste Pollicino, Valerio Lubello, Marco Bassini Canterano.

http://www.aracneeditrice.it/aracneweb/index.php/pubblicazione.html? item $=9788854896703 \&$ tab $=$ indice

12. Navas, Susana. 2019. Digital Content of the Inheritance: Remarks on the Judgment of the German Federal Court of Justice (BGH) of 12 July 2018 from the Standpoint of Spanish Law.aEuropean Review of Private Law 27(5): 1159 Ts 1168.

13. Nemeth, Kristin and Jorge Morais Carvalho. 2017. Digital inheritance in the European Union.aJournal of European Consumer and Market Lawa6(6): 253-260.

14. Novoselova, Ludmila and Oleg Polezhaev. 2019. Digital signs as objects of civil rights. Entrepreneurial Law 4: 3-12.

15. Patti, Francesco Paolo and Francesca Bartolini. 2019. Digital Inheritance and Post Mortem Data Protection: The Italian Reform.aEuropean Review of Private Law (ERPL), Forthcoming. https://papers.ssrn.com/sol3/papers.cfm?abstract_id $=3397974$

16. Pike, George. 2014. Legal Issues: What to Do with Your Digital Life.a http://dx.doi.org/10.2139/ssrn.2963660 
17. PWC. 2013. UDigital lives: we value our assets at ?25 billion.F Accessed May 12, 2021. https://pwc.blogs.com/press room/2013/12/uk-consumers-value-their-digitallives-at-25-billion-.html

18. Rackpace Hosting. 2011. UGeneration Cloud: A social study into the impact of cloud-based services on everyday UK life.F Accessed April 15, 2021.

https://slidex.tips/download/generation-cloud-a-social-study-into-the-impact-of-cloudbased-services-on-every.

19. Revised Uniform Fiduciary Access to Digital Assets Act (RUFADAA, 2014) Accessed April 15, 2021. https://leginfo.legislature.ca.gov/faces/billTextClient.xhtml

20. Ruan, Keyun. 2019.aDigital Asset Valuation and Cyber Risk Measurement: Principles of Cybernomics. Academic Press.

21. Sannikova, Larisa and Julia Kharitonova. 2018a. The legal entity of new digital assets. Law 9: 86-95.

22. Sannikova, Larisa and Julia Kharitonova. 2018b. Protection of digital assets as property value. Economy and law 5: 26-35.

23. Santos Moron, Mar?a. 2018. The So-Called Digital Inheritance: Need of Regulation: Study of Spanish and Comparative Law.aCuadernos Derecho Transnacionala10(1): 413438.

24. Sarnek, Marcin. 2016. When You Are Not What You Do Not Have: Some Remarks on Digital Inheritance.aIn Materiality and Popular Culture: The Popular Life of Things, edited by Anna Malinowska, Karolina Lebek. New York: Routledge.

25. Saveliev Alexander. 2017. Cryptocurrencies in the system of civil rights objects. Law 8: 136-153.

26. Vu?kovi?, Romana and Ivana Kanceljak. 2019. Does the right to use digital content affect our digital inheritance?aEU and comparative law issues and challenges series (ECLIC)a3: 724-746. https://doi.org/10.25234/eclic/9029

27. Wei-jie, Wang. 2012. Research on the Present Situation of Chinese Digital Inheritance.ahttp://en.cnki.com.cn/Article_en/CJFDTOTAL-QBKX201201009.htm

28. Yatsenko, Tatyana. 2019. Inheritance of digital rights. Inheritance Law 2: 11-14.

29. Zhao, Li, Xi-ye Li and Shu-hui Yang. 2012. Succession of Digital Inheritance Involving Accounts.aJournal of Beijing University of Posts and Telecommunications (Social Sciences Edition) 14 (3): 33 39.ahttps://journalsk.bupt.edu.cn/EN/Y2012/V14/I3/33 


\section{Харитонова Юлия Сергеевна}

Lomonosov Moscow state University

Moscow, Russia

\section{Аннотация}

Ключевые слова:

Дата публикации: 02.07.2021

\section{Ссылка для цитирования:}

Харитонова Ю. С. // Law \& Digital Technologies. - 2021. - Т. 1. - Vol. 1 №1 C. 19-26 . URL: https://ldt-journal.com/s123456780015732-6-1/. DOI:

$10.18254 / \mathrm{S} 123456780015732-6$ 